\title{
Waarde van werk in Nederland: de rol van de organisatie
}

\author{
Wieteke Conen \& Paul de Beer*
}

\section{Inleiding}

Zowel de Wetenschappelijke Raad voor het Regeringsbeleid (WRR), in het rapport Het betere werk (2020), als de commissie-Borstlap, in het advies In wat voor land willen wij werken? (2020), heeft recent de aandacht gericht op de waarde en kwaliteit van werk. Waar de afgelopen drie decennia de bevordering van de arbeidsparticipatie centraal stond in het overheidsbeleid, pleiten de WRR en de commissieBorstlap nu voor meer nadruk op de kwalitatieve kant van werk in Nederland. Extrinsieke aspecten nemen hierin een belangrijke plaats in, zoals de kwaliteit van baankenmerken in de vorm van werkzekerheid, inkomenszekerheid en beloning. Met de toenemende technologisering en flexibilisering van werk lijkt met name op dit terrein een aanzienlijke kwetsbare groep werkenden te (zijn) ontstaan; ook de huidige coronapandemie treft hier een zenuw (De Ruiter, 2020). Daarnaast blijkt uit genoemde rapporten dat werk in de loop van de tijd intensiever is geworden en er is een toenemende behoefte ontstaan aan het kunnen combineren van taken en functies. Ruim aandacht wordt tevens besteed aan - voor Nederlandse werkenden belangrijke - intrinsieke aspecten van werk (zoals het doen van inhoudelijk leuk werk, autonomie en ontplooiingsmogelijkheden), sociale contacten op het werk en de maatschappelijke betekenis van het werk. Dat het laatste ook in bredere zin interesse wekt, blijkt onder meer uit de ruime (publieke) belangstelling voor het boek Bullshit jobs van David Graeber (2018), die claimt dat een aanzienlijk deel van de werkenden zinloos werk doet.

Echter, in de (maatschappelijke) discussie over de waarde van werk zijn tot nog toe verschillende aspecten onderbelicht gebleven. Eén daarvan is dat de aandacht zich vooralsnog vooral richt op (aspecten van) de individuele baan, zonder context of inbedding. Dit terwijl banen van werknemers - toch nog steeds de grootste groep werkenden op de arbeidsmarkt - per definitie deel uitmaken van een arbeidsorganisatie. In deze bijdrage richten we ons op de vraag hoe de waardering van werk - naast kenmerken van het individu en van de baan - wordt beïnvloed door (a) kenmerken van de organisatie (hierbij valt te denken aan de omvang van een bedrijf of instelling, de samenstelling van het personeelsbestand en het hebben van een winstdoelstelling), (b) de manier waarop werknemers en werkgevers met elkaar omgaan, en (c) de mate waarin werknemers hun waarden hierbinnen weten te realiseren. Op basis van een recent gehouden survey onder de Neder-

* Dr. Wieteke Conen is werkzaam als onderzoeker bij AIAS-HSI, Universiteit van Amsterdam. Prof. dr. Paul de Beer is hoogleraar arbeidsverhoudingen bij AIAS-HSI, Universiteit van Amsterdam. 
landse bevolking, de Waarde van Werk Monitor (de WWM 2019), willen we hier meer licht op werpen.

\section{Waarde van Werk Monitor 2019}

De gegevens voor deze bijdrage zijn afkomstig uit de Waarde van Werk Monitor (WWM), waarvan de eerste meting in het voorjaar van 2019 heeft plaats gevonden onder bijna 3500 Nederlanders van 18-70 jaar. De WWM is opgezet om de waarde(ring) van werk onder de Nederlandse bevolking in kaart te brengen in relatie tot de organisatie- en institutionele context. Belangrijke thema's in de enquête zijn maatschappelijke participatie, waarde(ring) van betaald en onbetaald werk in het algemeen, tijdsbesteding, waarde(ring) van de huidige betaalde werkkring, de arbeidsorganisatie en de rol van instituties. In deze eerste golf van de WWM werd een respons gerealiseerd van 41 procent. Dit percentage is redelijk vergelijkbaar met ander surveyonderzoek op dit terrein. De non-respons op de afzonderlijke items waarvan in dit artikel gebruik wordt gemaakt, is lager dan 3 procent. Ten opzichte van de totale populatie in Nederland bevat de steekproef relatief weinig respondenten die in het buitenland zijn geboren, of van wie ten minste één ouder in het buitenland is geboren. We beschouwen de bevindingen uit dit onderzoek daarom alleen als representatief voor mensen zonder migratieachtergrond. Voor de analyses in dit artikel zijn de data gewogen om te corrigeren voor verschillen in de sociodemografische kenmerken van de steekproef ten opzichte van de doelpopulatie (zie ook Conen \& De Beer, 2020).

\section{Belang van verschillende aspecten}

Vaak wordt verondersteld dat alle werknemers ongeveer dezelfde waarde toekennen aan verschillende aspecten van het werk. De mate waarin mensen belang hechten aan baankenmerken als werkzekerheid, loon, autonomie en inhoud kan echter verschillen. Inzicht hierin is van belang om te bepalen voor wie de kwaliteit van het werk tekortschiet. Immers, op het moment dat iemand weinig waarde hecht aan werkzekerheid ('leuk voor erbij') of inhoudelijk interessant werk ('gewoon wat geld verdienen'), is het ook minder knellend wanneer dit aspect niet aanwezig is in de huidige baan. Tabel 1 laat zien dat er tussen de respondenten inderdaad variatie is in het belang dat zij aan verschillende baankenmerken hechten.

De tabel laat zien hoe belangrijk Nederlandse werkenden verschillende aspecten van hun werk vinden. De literatuur op dit terrein onderscheidt verschillende hoofddimensies (Harpaz \& Fu, 2002; Kalleberg \& Marsden, 2013; Hauff \& Kirchner, 2015). In de eerste plaats is er het onderscheid tussen 'extrinsieke' en 'intrinsieke' oriëntaties. Extrinsieke oriëntaties beklemtonen het belang van waarden op het gebied van inkomen, arbeidsomstandigheden en -voorwaarden en zekerheid; intrinsieke oriëntaties hebben betrekking op het belang van inhoudelijk interessant werk en het kunnen benutten en ontplooien van eigen capaciteiten. Naast 
deze twee basisdimensies zijn er meer 'sociale' en 'maatschappelijke' aspecten van werk die inhoudelijk noch tot de ene, noch tot de andere dimensie gerekend kunnen worden. In de Waarde van Werk Monitor kunnen respondenten aangeven hoe belangrijk verschillende aspecten voor hen zijn. De antwoordmogelijkheden (4-puntsschaal) variëren van 'zeer belangrijk' tot 'helemaal niet belangrijk'. In de laatste kolom is de gemiddelde score vermeld op een schaal van 1 (= helemaal niet belangrijk) tot 4 (= zeer belangrijk). Deze gemiddelde score varieert van 2,57 tot 3,67 , hetgeen betekent dat de meeste aspecten tamelijk belangrijk worden gevonden.

Met name intrinsieke aspecten van het werk, zoals inhoudelijk leuk werk en de sociale dimensie ('prettige mensen om mee te werken'), zijn voor een groot deel van de Nederlandse werkenden 'zeer belangrijk' of anders toch 'tamelijk belangrijk'. Ook extrinsieke aspecten van werk als 'een goed loon', 'goede werktijden' en 'zekerheid' worden door een overgrote meerderheid belangrijk gevonden, maar worden minder vaak als 'zeer belangrijk' aangemerkt. Aan de maatschappelijke betekenis van het werk, zoals 'werk waarin je andere mensen kunt helpen' en 'een baan die nuttig is voor de samenleving', wordt duidelijk minder belang gehecht, maar deze wordt toch nog door een meerderheid van de werkenden belangrijk gevonden. 
Tabel 1 Het belang dat men aan verschillende kenmerken van het werk hecht (werkzame beroepsbevolking, 18-70 jaar) (in procenten)

\begin{tabular}{|c|c|c|c|c|}
\hline & $\begin{array}{l}\text { Zeer } \\
\text { belangrijk } \\
\text { (4) }\end{array}$ & $\begin{array}{c}\text { Tamelijk } \\
\text { belangrijk } \\
\text { (3) }\end{array}$ & $\begin{array}{l}\text { Totaal } \\
\text { 'belangrijk' } \\
(4 \text { en } 3 \\
\text { tezamen) }\end{array}$ & $\begin{array}{c}\text { Gemid- } \\
\text { delde } \\
\text { (schaal van } \\
\text { I-4) }\end{array}$ \\
\hline \multicolumn{5}{|l|}{ Extrinsiek } \\
\hline Goed loon/salaris & 34 & 59 & 93 & 3,27 \\
\hline Goede werktijden & 35 & 51 & 86 & 3,19 \\
\hline Zekerheid & 37 & 48 & 85 & 3,19 \\
\hline Goede vakantieregeling/veel vakantie & 23 & 53 & 76 & 2,97 \\
\hline \multicolumn{5}{|l|}{ Intrinsiek } \\
\hline Inhoudelijk leuk werk & 69 & 29 & 98 & 3,67 \\
\hline Werk waar je zelf trots op bent & 48 & 45 & 93 & 3,40 \\
\hline Ruimte om initiatief te tonen & 42 & 49 & 91 & 3,34 \\
\hline Leren van nieuwe dingen & 38 & 51 & 89 & 3,26 \\
\hline $\begin{array}{l}\text { Werk waarin je jezelf kunt ont- } \\
\text { plooien of ontwikkelen }\end{array}$ & 37 & 52 & 88 & 3,26 \\
\hline $\begin{array}{l}\text { Een werkkring waar je merkt dat je } \\
\text { iets kunt bereiken }\end{array}$ & 27 & 52 & 79 & 3,06 \\
\hline \multicolumn{5}{|l|}{ Sociaal en maatschappelijk } \\
\hline Prettige mensen om mee te werken & 63 & 35 & 97 & 3,60 \\
\hline $\begin{array}{l}\text { Werk waarin je andere mensen kunt } \\
\text { helpen }\end{array}$ & 27 & 47 & 73 & 2,97 \\
\hline $\begin{array}{l}\text { Een baan die nuttig is voor de samen- } \\
\text { leving }\end{array}$ & 20 & 46 & 65 & 2,82 \\
\hline $\begin{array}{l}\text { Werk waarin je bijdraagt aan het } \\
\text { oplossen van sociale, maatschappe- } \\
\text { lijke of milieu-gerelateerde proble- } \\
\text { men }\end{array}$ & 15 & 38 & 51 & 2,57 \\
\hline
\end{tabular}

Bron: WWM 2019, eigen berekeningen, gewogen data.

\section{De organisatie in beeld}

Als de respondenten wordt gevraagd 'Hoe tevreden of ontevreden bent $\mathrm{u}$, alles bij elkaar genomen, met uw huidige werk?' geven zij gemiddeld een rapportcijfer van 7,6 . Met behulp van een multivariate regressieanalyse gaan we allereerst na in hoeverre de tevredenheid met het werk samenhangt met de aard van de arbeidsrelatie, kenmerken van de organisatie en de inbedding van de werknemer in de organisatie (model I in tabel 2). Als kenmerken van de organisatie nemen we de sector, de grootte van de organisatie, de financiële situatie (slecht tot zeer goed) en de eigendomsvorm (familiebedrijf, overheid of non-profit en overig) in de analyse mee. Hierbij wordt gecontroleerd voor een aantal individuele kenmerken en kenmerken van het huishouden. 
Tabel 2 Arbeidstevredenheid, werknemers in loondienst (18-70 jaar) (regressieanalyse)

\begin{tabular}{|c|c|c|c|c|}
\hline & \multicolumn{4}{|c|}{ Arbeidstevredenheid } \\
\hline & \multicolumn{2}{|c|}{ Model I } & \multicolumn{2}{|c|}{ Model II } \\
\hline & B & $\begin{array}{l}\text { standaard- } \\
\text { fout }\end{array}$ & B & $\begin{array}{l}\text { standaard- } \\
\text { fout }\end{array}$ \\
\hline \multicolumn{5}{|l|}{$\begin{array}{l}\text { Positie in de hoofdbaan of } \\
\text { hoofdwerkkring } \\
\text { (ref.=vast contract) }\end{array}$} \\
\hline Tijdelijk, uitzicht op vast & 0.147 & $(0.093)$ & $0.228 *$ & $(0.089)$ \\
\hline $\begin{array}{l}\text { Tijdelijk, geen uitzicht op } \\
\text { vast }\end{array}$ & -0.019 & $(0.114)$ & 0.158 & $(0.115)$ \\
\hline Oproep/inval/uitzendkracht & -0.118 & $(0.126)$ & 0.104 & $(0.132)$ \\
\hline
\end{tabular}

\section{Organisatiekenmerken}

Sector (ref.=Landbouw, tuin-

bouw, visserii)

$\begin{array}{lllll}\text { Industrie, bouwnijverheid } & -0.073 & (0.201) & -0.103 & (0.196) \\ \text { Private dienstverlening } & 0.015 & (0.191) & 0.082 & (0.187) \\ \text { Publieke dienstverlening } & 0.070 & (0.199) & 0.055 & (0.193)\end{array}$

Omvang (ref.=klein $(<50$ werknemers))

\begin{tabular}{|c|c|c|c|c|}
\hline $\begin{array}{l}\text { Middel (50-250 werk- } \\
\text { nemers) }\end{array}$ & -0.041 & $(0.093)$ & 0.036 & $(0.088)$ \\
\hline Groot (>250 werknemers) & -0.040 & $(0.079)$ & 0.038 & $(0.075)$ \\
\hline $\begin{array}{l}\text { nciële situatie bedrijf (I } \\
\text { ht' tot } 4 \text { 'zeer goed') }\end{array}$ & $0.133 * *$ & $(0.033)$ & $0.104 * *$ & $(0.03 I)$ \\
\hline \multicolumn{5}{|l|}{ m (ref.=overig) } \\
\hline Familiebedrijf & 0.103 & $(0.084)$ & 0.059 & $(0.08 \mathrm{I})$ \\
\hline Overheidsinstelling of & -0.053 & $(0.072)$ & -0.069 & $(0.068)$ \\
\hline
\end{tabular}

\section{Samenstelling personeelsbe-} stand

(I '(bijna) geen' tot 5 '(bijna) iedereen)

$\begin{array}{lllll}\text { Deeltijd } & 0.015 & (0.022) & 0.018 & (0.021) \\ \text { Vast contract } & 0.063^{*} & (0.031) & 0.027 & (0.029) \\ \text { Langdurige tijdelijke contracten } & 0.069 & (0.037) & 0.061 & (0.036) \\ \text { Uitzend- of oproepcontracten } & 0.011 & (0.027) & 0.013 & (0.025) \\ \begin{array}{l}\text { Ingehuurde zelfstandigen of free- } \\ \text { lancers }\end{array} & -0.096^{*} & (0.048) & -0.10 I^{*} & (0.046)\end{array}$

\section{Relatie werknemer - organisatie}

$\begin{array}{lllll}\text { Bijscholing } & 0.179 * * & (0.026) & 0.145 * * & (0.025) \\ \text { Inbedding/loyaliteit } & 0.269 * * & (0.022) & 0.235 * * & (0.022)\end{array}$




\begin{tabular}{|c|c|c|c|c|}
\hline & \multicolumn{4}{|c|}{ Arbeidstevredenheid } \\
\hline & \multicolumn{2}{|l|}{ Model I } & \multicolumn{2}{|l|}{ Model II } \\
\hline & B & $\begin{array}{l}\text { standaard- } \\
\text { fout }\end{array}$ & B & $\begin{array}{l}\text { standaard- } \\
\text { fout }\end{array}$ \\
\hline \multicolumn{5}{|l|}{ Autonomie } \\
\hline $\begin{array}{l}\text { Zelf bepalen hoe ik werk uit- } \\
\text { voer }\end{array}$ & $0.057^{*}$ & $(0.029)$ & $0.068^{*}$ & $(0.029)$ \\
\hline Eigen werktijden bepalen & $0.166 * *$ & $(0.034)$ & $0.149 * *$ & $(0.032)$ \\
\hline Ruimte initiatief & $0.45 I^{* *}$ & $(0.032)$ & $0.293^{* *}$ & $(0.032)$ \\
\hline Werkintensiteit & $-0.245^{* *}$ & $(0.044)$ & $-0.247 * *$ & $(0.043)$ \\
\hline \multicolumn{5}{|l|}{$\begin{array}{l}\text { Kloof tussen belang en ken- } \\
\text { merken }\end{array}$} \\
\hline Loon & & & $-0.322 * *$ & $(0.077)$ \\
\hline Zekerheid & & & $-0.30 \mathrm{I} * *$ & $(0.095)$ \\
\hline Vakantieregeling & & & -0.036 & $(0.087)$ \\
\hline Inhoudelijk & & & $-1.038 * *$ & $(0.126)$ \\
\hline Trots & & & $-0.742 * *$ & $(0.124)$ \\
\hline Sociaal & & & $-0.957 * *$ & $(0.162)$ \\
\hline Gecorrigeerde $\mathbf{R}^{2}$ & 0.402 & & 0.488 & \\
\hline$N$ & $\mathrm{I}, 773$ & & $\mathrm{I}, 773$ & \\
\hline
\end{tabular}

Gecontroleerd voor: geslacht, leeftijd, opleiding, gezondheid, het hebben van een beperking, godsdienst/levensovertuiging, een (werkende) partner, thuiswonenden kinderen, inkomen en vermogen (huishouden).

* Significant bij $\mathrm{p}<0,05$.

** Significant bij $\mathrm{p}<0,0$ I.

Bron: WWM 2019, eigen berekeningen

Allereerst valt op dat als de kenmerken van de organisatie in de analyse worden opgenomen, de contractvorm geen significant effect heeft op de tevredenheid van de werknemer. Dit duidt erop dat een flexibel contract als zodanig geen positief of negatief effect heeft op de tevredenheid van werknemers, maar dat dit het gevolg is van andere kenmerken van de baan of van de organisatie. Van de algemene kenmerken van de organisatie heeft alleen de financiële situatie een significant effect: werknemers zijn meer tevreden naarmate de financiële situatie beter is. De sector, de omvang van het bedrijf en de eigendomsvorm hebben geen zelfstandig effect. Hoewel de contractvorm zelf geen significant effect heeft, zijn werknemers wel meer tevreden als hun organisatie verhoudingsgewijs meer vaste contracten en minder ingehuurde zelfstandigen en freelancers telt. Blijkbaar voelen werknemers zich prettiger in een organisatie waarin de meeste collega's een min of meer duurzame band met de organisatie hebben.

Daarnaast hebben we een tweetal indicatoren opgenomen voor de relatie tussen de werknemer en de organisatie. De eerste betreft de mate waarin organisaties investeren in hun werknemers in de vorm van (bij)scholing gedurende de loop- 
baan. Vinden werknemers dat zij voldoende bijscholing krijgen in de betreffende organisatie? De tweede betreft de inbedding in of loyaliteit van de werknemer met de organisatie (voorbeelditem: 'deze organisatie betekent veel voor mij'). Beide hebben een sterk positief effect op de tevredenheid van de werknemer. Ook de procedurele en de inhoudelijke autonomie van werknemers hebben een positief effect op de ervaren arbeidstevredenheid, terwijl de werkbelasting een negatief effect heeft op de tevredenheid van de werknemer.

In model II voegen we een aantal indicatoren toe voor de ervaren kloof tussen het belang dat de respondenten hechten aan verschillende baankenmerken (zoals weergegeven in tabel 1) en de mate waarin deze kenmerken gelden voor hun huidige werk. Deze kloof heeft de waarde ' 1 ' als respondenten een aspect belangrijk vinden terwijl dit aspect niet aanwezig is in hun huidige werk, en een waarde ' 0 ' in alle andere situaties. Bijvoorbeeld: als iemand zekerheid belangrijk vindt, maar dit niet binnen de huidige werkkring ervaart, heeft deze variabele de waarde ' 1 '. Voor alle kenmerken, met uitzondering van de vakantieregeling, geldt dat werknemers minder tevreden zijn als zij een kloof ervaren tussen het belang en de feitelijke aanwezigheid van een kenmerk.

\section{Discussie: hoe verder?}

Onze analyse laat zien dat het bij het beoordelen van de kwaliteit van het werk niet alleen van belang is te kijken naar de kenmerken van een arbeidsrelatie, maar ook naar de context van de organisatie waarin het werk plaatsvindt en naar de waarden van werkenden. Terwijl in de recente maatschappelijke discussie, waaronder de bijdragen van de WRR en de commissie-Borstlap, sterk de nadruk wordt gelegd op contractvormen, blijken andere aspecten van grote invloed op de tevredenheid van werknemers. Zo blijkt een groot aandeel ingehuurde freelancers of zelfstandigen in de organisatie de tevredenheid van de werknemers negatief te beïnvloeden. Hoewel we niet kunnen vaststellen of dit uiteindelijk doorwerkt in bijvoorbeeld de productiviteit van de werknemers, zouden werkgevers meer met dergelijke (indirecte) effecten rekening moeten houden. Ook de sterk positieve effecten van autonomie, bijscholingsmogelijkheden en de inbedding in de organisatie zouden meer aandacht verdienen bij beslissingen die organisaties nemen ten aanzien van hun personeelsbeleid. Tot slot hebben we laten zien dat het belangrijk is de kenmerken van een baan te relateren aan het belang dat de werkenden aan die kenmerken hechten.

Waar de focus op contractvorm het pad effent richting initiatieven die van 'buiten' op organisaties inwerken (middels bijvoorbeeld wetgeving of een rol voor vakbonden), komt door bovenstaande meer focus te liggen op het belang van initiatieven bínnen organisaties. Hier kan een rol liggen voor het humanresourcesmanagement, of wellicht voor 'chief happiness officers', in de zin dat zij binnen organisaties een prominentere rol zouden kunnen opnemen in de dialoog tussen werknemers en de organisatie. Maar daarnaast is het ook een vraag of dit (inderdaad) bij hrm hoort of meer integraal in organisaties een tak van sport zou moe- 
ten worden om deze afstemming te vinden. In hoeverre weten organisaties wat hun werknemers belangrijk vinden, of zij voldoende bijscholing ontvangen, in hoeverre werknemers zich ingebed weten, hoe zij autonomie - ook in relatie tot werkbelasting - ervaren, en waar eventueel een kloof zit? In hoeverre weten werknemers waarom organisaties bepaalde beslissingen nemen? Maar ook: in hoeverre weten managers zelf waarom ze bepaalde beslissingen nemen?

Aangezien het soms onvermijdelijk kan zijn dat een baan niet in alle opzichten een hoge kwaliteit heeft, zou het wenselijk zijn om de verdeling van werknemers over banen met verschillende kenmerken mede af te stemmen op hun preferenties. Mogelijk gebeurt dit nu al ten dele doordat werkzoekenden een baan zoeken die aansluit bij hun preferenties, maar organisaties zouden dit ook meer zelf kunnen bevorderen, bijvoorbeeld door medewerkers keuzemogelijkheden te bieden tussen verschillende baankenmerken. Zo is het denkbaar dat werknemers tot op zekere hoogte kunnen kiezen tussen de hoogte van het loon en de zekerheid van hun baan (een minder zeker contract zou dan gecompenseerd worden door een hoger loon) of de inhoud van het werk (een hoger loon voor inhoudelijk minder leuk werk). Een dergelijke benadering kan ertoe bijdragen dat de discussie over de waarde van werk zich minder concentreert op contractvormen en dat de rol van de werkgever meer in beeld komt.

\section{Literatuur}

Commissie-Borstlap (2020). In wat voor land willen wij werken? Eindrapport van de Commissie Regulering van Werk.

Conen, W.S., \& Beer, P.T. de (2020). De waarde van werk in Nederland: resultaten van de Waarde van Werk Monitor. Amsterdam: AIAS-HSI (te verschijnen).

Graeber, D. (2018). Bullshit jobs. New York: Simon \& Schuster.

Harpaz, I., \& Fu, X. (2002). The structure of the meaning of work: A relative stability amidst change. Human relations, 55 (6): 639-667.

Hauff, S., \& Kirchner, S. (2015). Identifying work value patterns: cross-national comparison and historical dynamics. International Journal of Manpower, 36 (2): 151-168.

Kalleberg, A.L., \& Marsden, P.V. (2013). Changing work values in the United States, 1973-2006. Social Science Research, 42 (2): 255-270.

Ruiter, M. de (2020, 15 maart). Corona treft vooral de zwakke broeders van de arbeidsmarkt: zzp'ers, oproep- en uitzendkrachten. De Volkskrant .

WRR (2020). Het betere werk. De nieuwe maatschappelijke opdracht (WRR-rapport 102). Den Haag: Wetenschappelijke Raad voor het Regeringsbeleid. 